\title{
Modernization of Education in Russia in the Interests of Sustainable Development: Problems and Prospects
}

\author{
Mariia Zadorina*, Veronika Meshcheryagina, Maria Vilacheva
}

\author{
Ural State University of Economics, Ekaterinburg, Russia \\ *Corresponding author.Email: zadorina@bk.ru
}

\begin{abstract}
The article is devoted to the formation of economic, environmental, social (spiritual, moral, legal) culture in the process of education in kindergartens, schools and colleges. The methodological basis of the research is general scientific and specific scientific methods and an interdisciplinary approach. Special attention is paid to the term "education" and learning outcomes. The authors come to the conclusion that the modernization of education in the interests of sustainable development requires solving a number of problems (lack of places in kindergartens, a small number of schools and teachers, etc.). The necessity of updating federal state educational standards (in terms of the formation of ecological, economic thinking and the foundations of legal thinking of pupils and students) is justified.
\end{abstract}

Keywords: Constitutional right, education, federal state educational standard, learning outcomes, sustainable development.

\section{INTRODUCTION}

The Russian Federation is a democratic, legal and social state (Part 1 of Article 1, Part 1 of Article 7 of the Russian Constitution). The policy in Russia is aimed at the comprehensive development of the individual and the sustainable development of the country. That is why a special place is given to education issues both in legislation and in political documents.

Education allows individuals to develop in the general cultural, social and professional spheres. The education system allows the state to meet the need for personnel and ensure the sustainable development of the economy. In this regard, education in the Russian Federation is recognized as the highest constitutional value. The legal rule of Part 1 of Article 43 of the Constitution of the Russian Federation establishes the right of everyone to education in the Russian Federation. At the same time, the category "education" is considered in several aspects.

First of all, it is a personal subjective right, an integral part of the legal status of a person and a citizen. In some cases, education can be considered as a duty [1]. In accordance with Part 4 of Article 43 of the Russian Constitution, basic general education is mandatory. At the same time, I.F. Nikitina [2] and T.E. Petrosyan [3] believe that education is freedom because of it is free from excessive state interference in the process of its implementation.

Secondly, education is a public service. The receipt of this service is guaranteed by the State. To do this, the authorities create new and support existing educational organizations. They carry out organizational, legal, managerial, financial and other activities to ensure that everyone has the opportunity to get an education. This understanding of the term "education" is associated with the concept of a service state. Nowadays, this concept is actively gaining popularity [4-5].

Thirdly, education is a single purposeful process of education and training [6]. The result of this process is knowledge, skills, values, experience and competencies. They are the basis of intellectual, spiritual and moral, creative, physical and (or) professional development of a person, satisfaction of his educational needs and interests.

Fourth, education is a system that includes the following elements: (1) educational documentation (for example, educational programs of various types, levels and directions) based on educational legislation (for example, federal state educational standards); (2) educational organizations and their staff (teachers, coaches, instructors, lecturers, professors, etc.); (3) individuals (pupils and students, their parents or legal representatives); (4) public authorities at federal, regional and municipal levels; (5) advisory bodies and expert 
analytical organizations that assess the quality of education; (6) legal entities (for example, employers) involved in the educational process. The education system functions due to the interconnection and interaction of its elements. Changing or upgrading one of its elements automatically leads to a change in all other elements.

In this regard, any study of education should take into account the polysemy of this term (legal, managerial, pedagogical and systemic aspects of the education). Therefore, an interdisciplinary approach is especially relevant for studying the modernization of education for sustainable development.

The purpose of the article is to identify the problems of modernization of education in Russia in the interests of sustainable development and propose ways to solve them. To do this, it is necessary to determine the result of the realization of the right to education, to analyze the legal framework of learning outcomes, to study statistical data on the provision of educational services, to consider the formation of economic, environmental, social (spiritual, moral, legal) culture among pupils and students, to identify the problems of functioning of the education system.

\section{MATERIALS AND METHODS}

The methodological basis of the research is general scientific (analysis, synthesis, comparison, induction, deduction, structural-functional and system methods) and specific scientific methods (formal-legal, statistical, specifically-sociological) and an interdisciplinary approach.

Material for research: the Constitution and other regulatory legal acts of the Russian Federation, scientific articles by Russian and foreign authors, analytical data of the authorities.

\section{RESULTS AND DISCUSSION}

The constitutional right to education is the basic and inalienable right to use the opportunities for obtaining knowledge, skills and abilities on the basis of mutual cooperation of the elements of the education system for the purpose of comprehensive personal development, preparation for life in society [7]

The result of the realization of the right to education is the receipt of a certain benefit by a person. This benefit is education as information, competencies, profession, etc. The specific characteristics of the benefit depend on the type and level of education.

The structure of education in Russia is established by Federal Law No. 273-FZ of December 29, 2012 "On Education in the Russian Federation". There are four types of education in Russia: general education, vocational education, additional education and vocational training. General education and vocational education have levels, additional education is divided into subtypes (Figure 1).

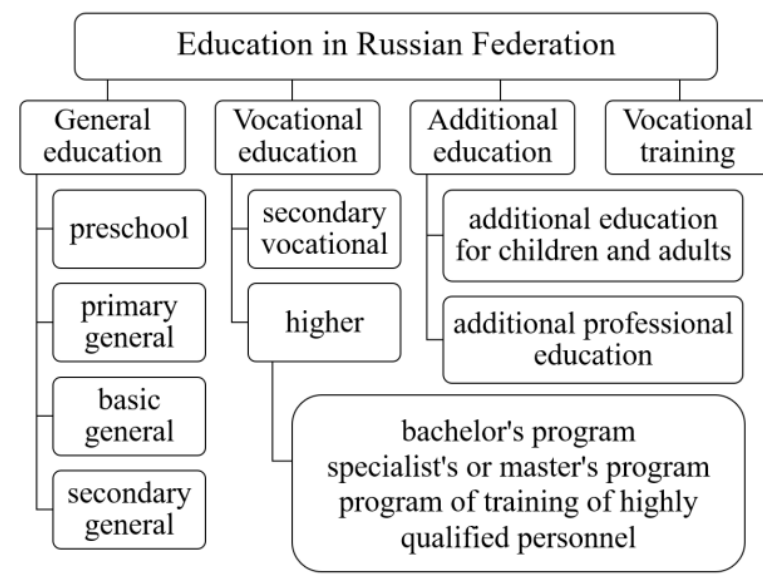

Figure 1. The structure of education in Russian Federation

It is necessary to note, that general education is divided into four levels: preschool education (kindergarten), primary general education (grades 1-4 of school), basic general education (grades 5-9 of school) and secondary general education (grades 10-11 of school). General education is divided into two levels: secondary vocational education (colleges, secondary vocational faculties and institutes of universities), higher education (only institutes and universities).

It is well known that education for sustainable development involves the formation of economic, environmental, social (spiritual and moral, legal) culture among pupils and students. Social and legal literacy, environmental and economic thinking are formed for a long time in the process of obtaining and assimilating knowledge, skills and abilities in the field of law, ecology, economics, etc. This process is implemented in accordance with the federal state educational standards. Different learning outcomes are provided for each type and level of education.

First of all, the federal state educational standard of preschool education defines the following reference point in the interests of sustainable development: (1) the child has a positive attitude to the world, to other people and to himself, has a sense of self-worth; (2) the child is capable of strong-willed efforts, can follow social norms of behavior and rules in different types of activities; (3) the child has basic knowledge about himself, about the natural and social world, has elementary ideas from the field of wildlife, natural science, mathematics, history, etc. These reference points are not checked. The first reason is the optional nature of preschool education. The second reason is that only some children receive preschool education. For example, some families have grandparents who can look after the child. In some 
families, mom or dad does not work and can take care of the child. However, most often children do not go to kindergartens due to lack of places (Figure 2). The coverage of children with preschool education is $69,4 \%$ in 2019 [8]. Preschool education access limitation is an important omission because of increasing evidence of early-life learning's large impacts on subsequent education and lifetime wellbeing [9].

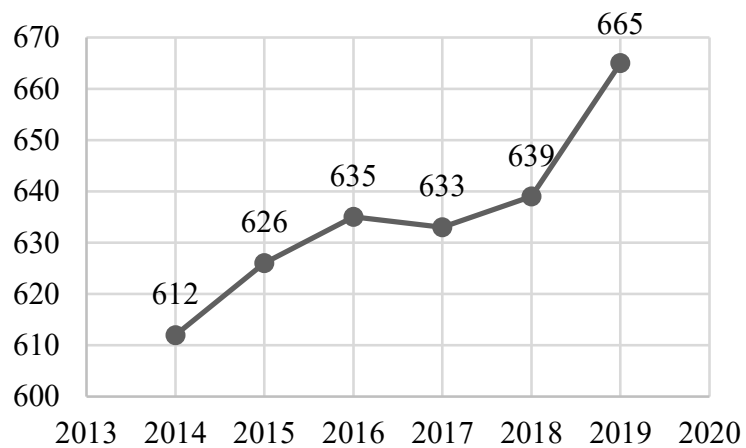

Figure 2 Number of places in kindergartens per 1000 children in Russia [8].

The comparison of the federal state educational standards of primary general, basic general and secondary general education allows us to trace the target results of training within the framework of environmental, spiritual and moral education, the formation of financial and legal literacy in children.

Ecological or environmental education is aimed at creating a respectful attitude towards nature in the interests of sustainable development [10]. Environmental education of children in primary school is aimed at forming a careful attitude to nature, rejection of actions that bring harm to it. Children are taught to apply knowledge from social and natural sciences to solve problems in the field of the environment in the basic general school. They learn to evaluate different actions and their possible consequences for the environment. It is assumed that the child is aware of the global nature of environmental problems and will be ready to take part in practical environmental activities. Moreover, the level of ecological culture should increase in children within the framework of basic general education. According to the results of training in secondary general school, children should have formed ecological thinking. They should understand the impact of socio-economic processes on the state of the natural and social environment. It is assumed that during the training period, children will gain experience in environmental-oriented activities.

It is necessary to agree with D. Narvaez that respect for the dignity of the individual and other people is a sign of a sustainable society [11]. That is why spiritual and moral education of children in primary school is aimed at recognizing the individuality of each person. In the process of teaching, children are taught to show empathy, respect and goodwill. Children should develop an aversion to any forms of behavior aimed at causing physical and moral harm to other people. In the basic general school, spiritual and moral education prepares children to be guided by moral values and norms in situations of moral choice, to evaluate behavior and actions from the position of moral and legal rules. It is assumed that children will form the freedom and responsibility of the individual in the conditions of individual and public space. They will not do antisocial things. Education in secondary general school forms the foundations of legal thinking.

Children are taught to apply basic mathematical knowledge in everyday situations (including for assessing personal and family finances) in the process of learning mathematics in primary school. Education in the basic general school is aimed at the formation of financial literacy. Children should be aware of themselves as consumers of financial services. They should learn to analyze household consumption, make a personal financial plan. These competencies should help them choose a profession in the future. As a result of receiving secondary general education, children should have an economic thinking formed. They must learn to make rational decisions in conditions of relative limited available resources, assess and take responsibility for their possible consequences for themselves, their environment and society.

Thus, the formation of ecological, economic thinking and the foundations of legal thinking among pupils is possible only in secondary general school (grades 10-11) as a result of studying Economics, Law and Ecology.

However, obtaining a general secondary education in Russia is not mandatory. Each child can independently decide what to do after the end of the 9th grade. First, he can continue his studies at school and get a general secondary education. Secondly, the child can go to college and get a secondary vocational education. Thirdly, he may not study further at all. In this case, there is no guarantee that the child will have formed an economic, environmental thinking and the basis of legal thinking. But secondary vocational education cannot guarantee this too.

The reason for this is that the federal state educational standard of secondary vocational education does not always provide for disciplines such as Economics, Law and Ecology, as well as the formation of economic, environmental thinking and the basics of legal thinking as one of the results of the appropriate educational program. As a result, graduates of non-environmental college programs have a superficial knowledge of the nature and its impact on societies. Most of them do not know the basics of environmental management and ecological-economic risks [12].

For example, the federal state educational standard of secondary vocational education in the specialty "Law and 
organization of social security" does not provide for the mandatory study of Economics and Ecology. The Federal State educational standard of secondary vocational education in the specialty "Economics and Accounting" does not provide for the study of Law and Ecology. At the same time, the federal state educational standard of secondary vocational education in the specialty "Rational use of natural resource complexes" provides for the study of Ecology, the Economics of nature management, as well as the Legal foundations of professional activity. As a result, environmental technicians and environmental protection specialists acquire the necessary knowledge, skills and abilities that allow them to assess economic damage and risks to the environment, the economic efficiency of environmental protection measures and fees for the use of natural resources.

One should consider the fact that more and more people in Russia prefer secondary vocational education (Figure 3). Therefore, it would be necessary to update the federal state educational standards for the sustainable development of the country. So, each student will have the opportunity to form environmental, economic thinking and the basics of legal thinking in college or secondary vocational faculties and institutes of universities.

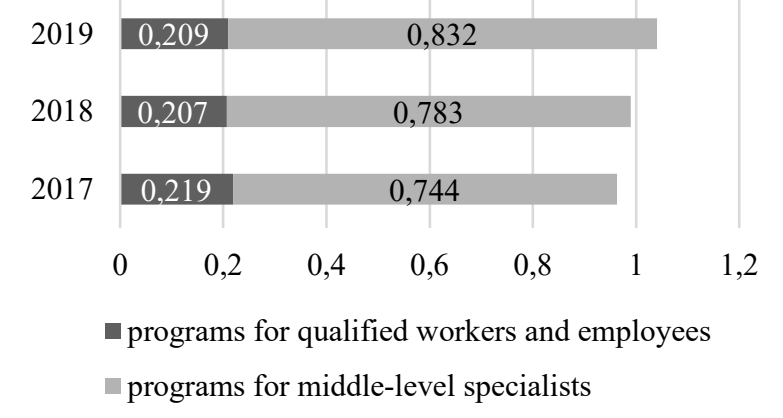

Figure 3 The number of applicants for educational programs of secondary vocational education in Russian Federation, million people [8].

However, less attention is paid to formation of prerequisites for financial and legal literacy in kindergartens. Moreover, "in most educational organizations, the solution to the problems of educating ecological culture still remains at the level of declarations" [13]. Nevertheless, a child at preschool age actively acquires his own experience, creates his own knowledge and meanings, builds interactions in shared activities and in communication with other children and adults. Thus, knowledge and meanings are not mechanically assimilated. They are actively created (constructed) by the child (himself) in the process of interaction with the natural and social world. In this regard, it is very important to strengthen the educational components that have value for sustainable development in the federal state educational standard of preschool education.

Table 1. The number of school pupils and teachers in Russian Federation, million people [8]

\begin{tabular}{|c|c|c|}
\hline Year & $\begin{array}{c}\text { The number of } \\
\text { school pupils }\end{array}$ & $\begin{array}{c}\text { The number of } \\
\text { school teachers }\end{array}$ \\
\hline 2005 & 15,1 & 1,5 \\
\hline 2010 & 13,3 & 1 \\
\hline 2015 & 14,5 & 1 \\
\hline 2019 & 16,5 & 1 \\
\hline
\end{tabular}

In addition, not all of the previously considered learning outcomes are fully achieved. There are several reasons for poor acquisition of competencies that are important for sustainable development. On the one hand, there is a shortage and congestion of schools: $13,2 \%$ of children study in the second or third shifts [8]. On the other hand, this is a lack of the number of teachers (Table 1). The profession of a teacher today is not prestigious and highly paid. The number of school pupils increased by 1,1 million people in the period from 2005 to 2019 , and the number of teachers decreased by 0,5 million people in the same period. If there were 10 children per teacher in 2005 , then there were already 16 17 children in 2019 [8]. The current conditions have a negative impact on the quality of education, reducing the pace of sustainable economic development.

\section{CONCLUSIONS}

Education is the result of the realization of the right to education as the set of learning outcomes that depend on the federal state educational standards. These standards regulate the ability to form an economic, environmental, social (spiritual, moral, legal) culture among pupils and students.

An interdisciplinary approach to education has made it possible to identify the problems of modernization of education in the interests of sustainable development: lack of places in kindergartens; a small number of schools and teachers; the orientation of federal educational standards to non-mandatory secondary general education in the formation of ecological, economic thinking and the foundations of legal thinking.

For the successful modernization of education in Russia in the interests of sustainable development, it is necessary to implement the following recommendations.

First, it is necessary to modernize federal state educational standards taking into account the interests of sustainable development. In this regard, it is necessary to update the federal state educational standards of secondary vocational education. As a result, each of them should include the formation of economic, environmental thinking and the foundations of legal thinking among the educational results. Thus, it will be possible to expand the number of young people involved in the process of 
forming financial, ecological and legal literacy of the population. In addition, the content of the federal state educational standard of preschool education should be updated so that the educational components that have value for sustainable development are strengthened.

Secondly, we need to create more preschool educational organizations, we need to build more schools. This is the only way to provide an opportunity for every child to study in the first shift (from 8 am to 14 $\mathrm{pm}$ ) and ensure equal access to preschool education.

Thirdly, it is necessary to increase the prestige of the teaching profession. The prestige of the profession can be affected by both material (an increase in wages, the introduction of new benefits and payments, etc.) and moral incentives (awarding special titles, awarding awards for conscientious work, etc.). It is especially important to develop a system of incentives for young professionals who have recently received professional education and are going to work in kindergarten or school for the first time.

Fourth, the Government should increase spending on education, since the socio-economic situation of the country, the growth rate of the population's well-being, the state of law and order, and the state of the environment largely depend on the state of the education system.

\section{AUTHORS' CONTRIBUTIONS}

All authors contributed to the design and implementation of the research. M. Vilacheva analysed data and legislation on preschool education, V. Meshcheryagina analysed data and legislation on primary general and basic general education, M. Zadorina analysed data and legislation on secondary general and secondary vocational education. All authors discussed the results and contributed to the final manuscript.

\section{REFERENCES}

[1] M.A. Zadorina, The right to education as a duty, freedom and constitutional value. In: V.M. Artemov (Eds.), The moral dimension and the human potential of law, 2017, pp. 185-192.

[2] I.F. Nikitina, Constitutional characteristics of the right to education. In: Law and education, 1 (2003) pp. 29-36.

[3] T.E. Petrosyan, On the question of the content, constitutional-legal nature and ontology of the constitutional right to education. In: Law and Education, 3 (2014) pp. 34-39.

[4] A.S. Falina, The service state: the origins of theory, elements of practice. In: Sociology of power, 1 2012, pp. 132-140.
[5] O.V. Romanovskaya, The political and legal doctrine of M. Rothbard and the foundations of the service state in Russia. In: Science. Society. State, 6 (1) (2018) pp. 20-26.

[6] V.E. Ljovkin, A.O. Ljovkina, E.L. Docenko, L.M. Volosnikova, The Idea of Education: Development or Service Delivery? In: The Education and science journal, 22(4) (2020) pp. 9-42. DOI: https://doi.org/10.17853/1994-5639-2020-4-9-42.

[7] T.N. Matyusheva, The constitutional right of a person and a citizen to education in the Russian Federation: the formation and development of the concept. In: Modern law, 1 (2009) pp. 13-18.

[8] O.Yu. Dudorova, Education, in: S.M. Okladnikov (Eds.), Regions of Russia. In: Socio-economic indicators, Rosstat, 2020, pp. 336-396.

[9] L.M. Richter, J.R. Behrman, P. Britto, et al., Measuring and forecasting progress in education: what about early childhood? In: Science of Learning, 6(1) (2021) p. 27. DOI: https://doi.org/10.1038/s41539-021-00106-7.

[10] O.V. Zakharova, L.G. Suvorova, M.V. Bogdanova, A.V. Zakharov, A. Permyakov, I.Y. Malykh, Environmental Education: Ecological Wisdom of Indigenous Peoples in Western Siberia. In: Sustainability, 13(7) (2021) p. 4040. DOI: https://doi.org/10.3390/su13074040.

[11] D. Narvaez, Moral education in a time of human ecological devastation. In: Journal of moral education, 50(1) (2020) pp. 55-67. DOI: $10.1080 / 03057240.2020 .1781067$.

[12] A.A. Salamatov, D.S. Gordeeva, The model of ontological reflection of ecological and economic value orientations formation in the process of vocational education. In: Education and science, 22(2) (2020) pp. 53-76. DOI: https://doi.org/10.17853/1994-5639-2020-2-53-77.

[13] M.N. Silantiev, E.I. Sharova, M.N. Kurochkina, F.M. Ordokova, G.A. Kyarova, Perspectives of environmental education and the formation of ecological culture among school children. In: International Journal of Educational Sciences, 31(13) (2020) pp. 61-66. DOI: https://doi.org/10.31901/24566322.2020/31.13.1147 . 